\title{
EFFICACY OF INTRA-ARTICULAR INJECTION OF SIMVASTATIN IN TREATMENT OF INTERNAL DERANGEMENT OF TEMPOROMANDIBULAR JOINT
}

\section{Mohamed Ashraf Abdel Fattah Mahmoud ${ }^{1}$, Abdel Badee Abdallah Abdel Mabood ${ }^{2}$, Gihan Gamal El Din El Desouky ${ }^{3}$, Eman Abdelhalim El Sharrawy ${ }^{4}$}

DOI: $10.21608 / d s u .2021 .52536 .1058$

Manuscript ID: DSU-2012-1058

\section{KEYWORDS}

Arthrocentesis,

Internal derangements,

MRI,Simvastatin,TMJ.

- E-mail address: dr_m_ashraf87@yahoo.com

1. Postgraduate student in Oral and Maxillofacial Surgery Department, Faculty of Dentistry, Suez Canal University

2. Assistant Professor of Oral and Maxillofacial Surgery, Faculty of Dentistry, Zagazig University

3. Professor of Oral Radiology, Faculty of Dentistry, Suez Canal University

4. Professor of Oral and Maxillofacial Surgery, Faculty of Dentistry, Suez Canal University

\section{ABSTRACT}

Introduction :ID management is one of challenges in maxillofacial filed. Almost $80 \%$ of adult symptomatic patients with TMD have some form of ID (1). Data from related literature has suggested that arthrocentesis may be of some benefit to manage symptoms of TMDs. Such a technique was first introduced for the management of sudden onset of closed lock

Aim : This study aimed to evaluate efficacy of simvastatin intra-articular injection in management of internal derangement (ID) of temporomandibular joint ( TMJ). Patients and methods: 15 patients with internal TMJ derangement were included in this study. All patients were subjected to preoperative clinical examination and preoperative magnetic resonance imaging (MRI) for the affected joints. The affected joints treated with arthrocentesis followed by intra-articular injection of $1 \mathrm{ml}$. simvastatin twice a month. Clinical follow up were done at 24 hours post- operatively, one week, one month and six months. Then, after six months MRI was repeated to compare with preoperative images. Results: Patients showed better results in comparison to preoperative parameters at 1 week, 4 and 24 weeks intervals. Patients showed better MRI findings in comparison to preoperative findings where position of the disc was almost returned to its normal anatomical position. Conclusion: Simvastatin intra-articular injection after arthrocentesis was effective technique for management of TMJ internal derangements symptoms.

\section{INTRODUCTION}

ID management is one of challenges in maxillofacial filed. Almost $80 \%$ of adult symptomatic patients with TMD have some form of ID. ${ }^{(1)}$ Data from related literature has suggested that arthrocentesis may be of some benefit to manage symptoms of TMDs. Such a technique was first introduced for the management of sudden onset of closed lock ${ }^{\cdot(1,2)}$

TMJ arthrocentesis is a lavage of upper joint space of TMJ done with no direct vision to remove necrotic tissue, blood and pain mediators from the joint. ${ }^{(3)}$ It is a basic underlying procedure for intra- articular treatment, including therapeutic arthrocentesis, and intra-articular injection of therapeutic substances. ${ }^{(4)}$ 
Simvastatins are group of drugs which have good results in regeneration of degenerated TMJ. Authors ${ }^{(5)}$ had conducted an experimental study that proved the injection of simvastatin hydrogel $5 \mathrm{mg} / \mathrm{ml}$ promotes autogenously chondrogenic disc repair and retard disc degeneration, which provides an alternative strategy for biological TMJ disc perforations repair in a less expensive and easily applied method. Recently, it has been suggested for intraarticular injection of TMJ with promising results ${ }^{(6)}$. Therefore, hypothesis of our study was if simvastatin hydrogel $5 \mathrm{mg} /$ $\mathrm{ml}$ was injected intraarticularly inside TMJ will promote autogenously chondrogenic disc repair . Accordingly, the purpose of the present study was to assess efficacy of simvastatin intra-articular injection in treatment of patients with TMJ Internal Derangement.

\section{PATIENTS AND METHODS}

15 adult patients suffering from internal derangement as approved by clinical and MRI examination were included in the current study. These patients were selected from those attending the outpatient clinic, of Oral and Maxillofacial surgery department of Faculty of Dentistry, Suez Canal University through period from 2018 to 2019.

\section{Inclusion criteria:}

a) Adult patients over 18 years of age.

b) Patients diagnosed with internal derangement of TMJ.

c) Patients with a chief complaint of TMJ pain and limited maximum mouth opening.

d) Patient with internal derangement as revealed in their MRI examination.

e) Patients unresponsive to conservative treatment modalities for TMJ dysfunction .

\section{Exclusion criteria:}

a) Patients with history of previous TMJ surgery.

b) Patients with limited mouth opening caused only by muscle spasm.

c) Patients with systemic inflammatory joint disease.

d) Patients with other pathological lesion in the joint.

e) Patients with direct trauma to the facial bones.

f) Patients with congenital disturbances as hyperplasia or hypoplasia of the joint.

g) Patients with osteoarthritic changes in TMJ bony components.

h) Patients with loss of normal TMJ disc architecture (over thinning or perforations).

i) Patients contraindicated to MRI (as patients with pacemakers, cerebral aneurismal clips, artificial cardiac valves, metal implants, hearing aids and claustrophobic patients).

\section{Preoperative Preparations:}

- Medical, dental histories, and history of chief complaint were taken.

- All selected patients were informed about the procedure, precautions, follow up appointments, possible complications. Also, they signed an informed consent.

\section{Preoperative clinical evaluation:}

- Pain scoring was carried out through a visual analogue scale (VAS) with 0 score for no pain and 10 score for worst pain experienced.

- Using a digital caliper, maximal unassisted mouth opening, Lateral, and protrusive movements were measured in millimeters. 
- Joint sounds as clicking or crepitation were evaluated preoperatively by palpation .The clicking was reported for each joint if present.

- All these measurements records were considered as a baseline to be used in comparison with postoperative records.

\section{Preoperative MRI Examination}

All patients were evaluated using MRI (open and closed) to diagnose internal derangement. The MRI was carried out in a private radiology center using with a 1.5T MR scanner (Gyroscan Intera Master; Philips Healthcare, Eindhoven, The Netherlands) and a dedicated, circular polarized transmit and receive TMJ coil. The MRI protocol included bilateral sagittal oblique proton density images of the right and left sides in both the closed mouth (maximum intercuspation) and maximum mouth opening positions. Examination also included bilateral coronal proton density images of the right and left sides at the closed mouth position.

\section{Drugs used with operative procedures}

1. Simvastatin: (calbiochem): $1 \mathrm{mg} / \mathrm{ml}$ Ampoule, Manufactured by EMD Millipore Crop., Billerica, MA USA. The injected dose was $(1 \mathrm{mg} / \mathrm{ml})$.

2. Sodium Hyaluronate: (Curavisc): 20mg / $2 \mathrm{ml}$ Syringe, Manufactured by IDT Biologika $\mathrm{GmbH}$ Company, Germany. The injected dose was $(1 \mathrm{mg} / \mathrm{ml})$.

\section{Operative procedures :}

\section{Arthrocentesis procedure:}

All patients carried out arthrocentesis procedure before injection material according to Nitzan (7) technique by drawing the canthal-tragus line and a point $10 \mathrm{~mm}$ in front of the tragus and $2 \mathrm{~mm}$ below the canthal-tragus line was marked to serve as the point of insertion of the first needle used as an inflow needle (red dot). Another point $20 \mathrm{~mm}$ in front of the tragus and $8 \mathrm{~mm}$ below the canthaltragus line (i.e. $10 \mathrm{~mm}$ anterior to the former one) was marked to serve as the point of insertion of the second needle used as an outflow needle (green dot) (Figure 1)

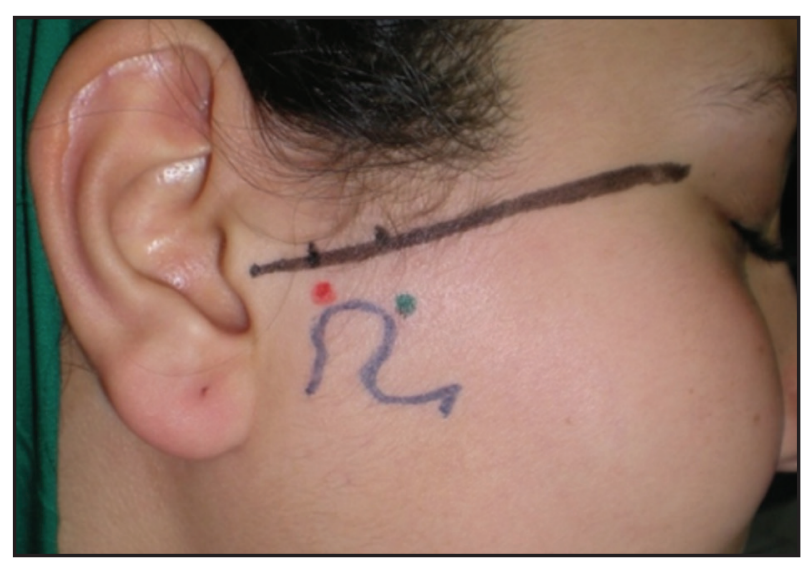

Fig. (1): Target areas marked with a washable felt-tip pen

- Local anesthesia of auriculotemporal nerve was admistrated using 0.3 to $0.5 \mathrm{ml}$ of an anesthetic solution 2\% Mepivacaine with 1/200000 Levonordefrin.

- A 20-guage needle was inserted at the marked first point and another one in the second marked point (Figure 2a).

- The joint was lavaged with $100-300 \mathrm{ml}$ ringer lactate solution injected into the upper joint compartment through inflow needle; the outflow needle was periodically occluded in order to create hydraulic pressure within the joint space. The patients were asked to open and close their mouth during the procedure to help outflow of the injected ringer lactate. 


\section{Injection of Simvastatin drug:}

After arthrocentesis had been performed for the affected joints, One $\mathrm{ml}$ of simvastatin containing $(5 \mathrm{mg})$ was injected intra-articularly. Patients were then asked to open their mouth and a needle was inserted at two target areas, the first target area was Posterior joint space and the second target is the anterior disc attachment. The standard program was to repeat the injections two times, at one month interval (Figure 2b).

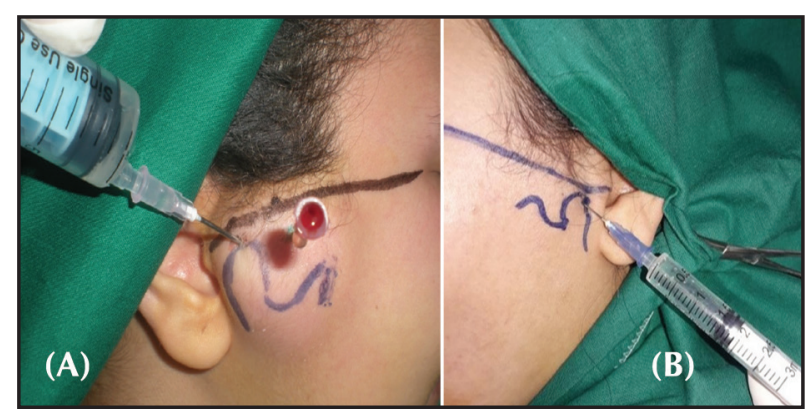

Fig. (2): A. Needles inserted at marked points. B. Injection of Simvastatin.

\section{Postoperative care and follow up:}

All patients were asked to follow the following instructions:

- Place cold application in the form of ice bags extra-orally for ten minutes every half an hour for the first 24 post-operative hours.

- Place hot fomentation extra-orally for ten minutes every half an hour for 1 week postoperatively.

- Maintain soft diet and avoid eating hard food, gum chewing for 1 week postoperatively.

- Gradually transform to normal diet within first postoperative week.
- Initiate physiotherapy exercises immediately postoperative.

- Drugs prescribed: Analgesic (brufen 600mg) every $12 \mathrm{~h}$ for 3 days.

\section{Clinical follow up:}

Postoperative clinical evaluation carried out at 24 hours postoperatively,

1 week, 1 month and 6 months after procedure to assess pain level, maximal mouth opening, lateral excursion movements, protrusive movements, joint sound.

\section{MRI follow up:}

MRI was taken 6 months postoperatively to assess disc displacement,disc position, disc shape, and retrodiscal tissues.

\section{Statistical analysis:}

Numerical data were collected and presented as mean and standard deviation values. Two - way ANOVA (analysis of variance) was used to evaluate effect of time on patients. The significance level was set at $P \leq 0.05$. Statistical analysis was performed with SPSS 17.0 ${ }^{\circledR}$ (Statistical Package for Scientific Studies) for Windows. Significance of the difference between both groups was evaluated using unpaired $\mathrm{t}$-test for independent samples.

\section{RESULTS}

Study included 15 patients (9 female and 6 male) with age ranged from 20 to 34 years. All patients tolerated injection procedures without any complications. 


\section{Pain score:}

Analysis of variance (ANOVA) test revealed that the mean pain with the lowest pain score was reached at the 6 month interval. The pain score significantly decreased by time post-operatively $(\mathrm{p}<0.0001)$. Preoperative measurements of pain revealed $8.15 \pm 0.93$. There was significant decrease in pain score after 24 hours as it was $6.90-1.55$ (p value $<0.0001)$. There was also decrease in pain score after 1 week to be $5.20 \pm 1.10$, after 1 month pain score was decreased to be $4.2 \pm 0.69$ and after 6 months pain score was $1.05 \pm 0.68$ (Table 1).

\section{Mouth opening:}

Analysis of variance (ANOVA) test revealed that the mean mouth opening values significantly increased by time post-operatively except after 24 hours with maximum mouth opening reached at 6 months interval. ( $<<0.0001$ ), (Table 6, Fig.23). Preoperative measurements of mouth opening revealed 19.90 \pm 5.389 . There was significant decrease in mouth opening after 24 hours as it was $17.40 \pm 4.370$ ( $\mathrm{p}$ value $<0.0001$ ). There was also increase in mouth opening after 1 week to be 24.00 \pm 5.400 , after 1 month mouth opening was increased to be $31.60 \pm 2.604$ and after 6 months mouth opening was $33.75 \pm 1.118$ (Table 1 ).

\section{Lateral excursion:}

Analysis of variance (ANOVA) test revealed that the mean lateral excursion values $(\mathrm{mm})$ significantly increased by time post-operatively except after 24 hours ( $\mathrm{p}<0.0001$ ), (Table 9, Fig.28). Preoperative measurements of lateral excursion revealed 14.15 \pm 3.28 . There was significant decrease in lateral excursion after 24 hours as it was
$13.65 \pm 2.46$ ( $\mathrm{p}$ value $<0.0001$ ). There was an increase in lateral excursion values after 1 week in comparison to preoperative and 24 hours values to be $15.50 \pm 2.6$, after 1 month lateral excursion also increased significantly to be $21.40 \pm 2.89$ and after 6 months lateral excursion increased $23.25 \pm 1.86$ (Table 1$)$.

\section{Protrusive movement:}

Analysis of variance (ANOVA) test revealed that the mean protrusive movement values $(\mathrm{mm})$ significantly increased by time post- operatively except after 24 hours $(\mathrm{p}<0.0001)$. Preoperative measurements of protrusive movement revealed $11.80 \pm 3.16$. There was significant decrease in protrusive movement values after 24 hours to be $10.35 \pm 2.21$ ( $\mathrm{p}$ value < 0.0001 ). Afterwards, a significant increase in mean protrusive movement values was seen through the follow up periods. There was increase in protrusive movement after 1 week to be $13.80 \pm 1.88$, after 1 month protrusive movement increased to be $17.85 \pm 2.23$ and after 6 months protrusive movement also increased to be $21.25 \pm 1.55$ (Table 1).

\section{Joint sounds:}

Analysis of variance (ANOVA) test revealed that the mean joint sounds with the lowest joint sounds score was reached at the 6 month interval. The joint sounds score significantly decreased by time postoperatively $(\mathrm{p}<0.0001)$. Preoperative measurements of joint sound revealed $8.15 \pm 0.93$. There was significant decrease in joint sounds score after 24 hours as it was $6.90 \pm 1.55$ ( $\mathrm{p}$ value $<0.0001$ ). There was also decrease in joint sounds score after 1 week to be $5.20 \pm 1.10$, after 1 month joint sounds score was decreased to be $4.20 \pm 0.69$ and after 6 months joint sounds score was $1.05 \pm 0.68$ (Table 1). 
Table (1): comparison between preoperative and postoperative clinical parameters

\begin{tabular}{|c|c|c|c|c|c|}
\hline & Pre- operative & $\mathbf{2 4}$ h P.O & 1 week P.O. & 1 month P.O & 6 months P.O \\
\hline \multicolumn{7}{|c|}{ Pain score } \\
\hline Mean & 8.15 & 6.90 & 5.20 & 4.20 & 0.69 \\
\hline SD & 0.93 & 1.55 & 1.10 & 136.34 & 0.68 \\
\hline F value & \multicolumn{7}{|c|}{$<0.0001^{*}$} & 31.60 & 33.75 \\
\hline P value & 19.90 & 17.40 & 24.00 & 2.604 & 1.118 \\
\hline \multicolumn{7}{|c|}{ Mouth opening (mm) } \\
\hline Mean
\end{tabular}

\begin{tabular}{|c|c|c|c|c|c|}
\hline \multicolumn{7}{|c|}{ ateral excursion $(\mathbf{m m})$} \\
\hline Mean & 14.15 & 13.65 & 15.50 & 21.40 & 23.25 \\
\hline SD & 3.28 & 2.46 & 2.60 & 2.89 & 1.86 \\
\hline F value & \multicolumn{5}{|c}{5.309} \\
\hline P value & \multicolumn{7}{|c|}{}
\end{tabular}

\begin{tabular}{|c|c|c|c|c|c|}
\hline \multicolumn{6}{|c|}{ Protrusive movement (mm) } \\
\hline Mean & 11.80 & 10.35 & 13.80 & 17.85 & 21.25 \\
\hline SD & 3.16 & 2.21 & 1.88 & 2.23 & 1.55 \\
\hline F value & \multicolumn{5}{|c|}{78.053} \\
\hline P value & \multicolumn{5}{|c|}{$<0.0001^{*}$} \\
\hline \multicolumn{6}{|c|}{ Joint sounds score } \\
\hline Mean & 8.15 & 6.90 & 5.20 & 4.20 & 1.05 \\
\hline SD & 0.93 & 1.55 & 1.10 & 0.69 & 0.68 \\
\hline F value & \multicolumn{5}{|c|}{136.34} \\
\hline P value & \multicolumn{5}{|c|}{$<0.0001^{*}$} \\
\hline
\end{tabular}

P.O. $=$ post operatively, $*$ Statistically significant at $p<0.05$ 


\section{MRI results:}

The thirty joints included in the present study were evaluated using MRI preoperatively, then after six months period from intraarticular injections of simvastatin . Preoperatively, all joints showed moderate to marked anterior disc displacement with reduction (reducible joints). Post-operative MRI results showed marked improvement in the disc position comparison to preoperative MRI.

\section{Analysis of MRI finding showed that:}

- Preoperatively, of the 18 joints with anterior disc displacement (60\%), a non-significant decrease in number was seen after 6 months where only 16 joints showed anterior disc displacement $(53.33 \%)$. While the remaining 12 joints with anteromedial disc displacement (40\%) preoperatively after 6 months, only 8 joints remained with anteromedial disc displacement $(26.66 \%)$.

- Regarding disc position: there was normal disc position in 22 joints preoperatively (73.33\%), a significant decrease in number was seen after 6 months where only 14 joints showed normal disc position $(46.67 \%)$.

Regarding patients with disc position in the intermediate zone, there was no difference in number of joints preoperatively and postoperatively. While the disc position in the posterior band, there was 4 joints (13.3\%) preoperatively with a non-significant decrease in number was seen after 6 months to be 2 joints $(6.67 \%)$.

- Regarding disc shape, biconcave disc shape was observed in 24joints preoperatively ( $80 \%$ ). There was significant decrease in patients' number with biconcave disc shape after 6 months as they were 20 joints(66.66\%).As far as the hemi convex disc shape there were 6joints with this disc shape (20\%) in patients in group I, after 6 months a decrease in number to 4 joints (13.33\%) was observed.

- The retrodiscal tissue showed no change between pre and post MR images as all patients showed normal signal. Therefore, a significant difference was only seen in normal disc position and biconcave disc shape (Figure 3).

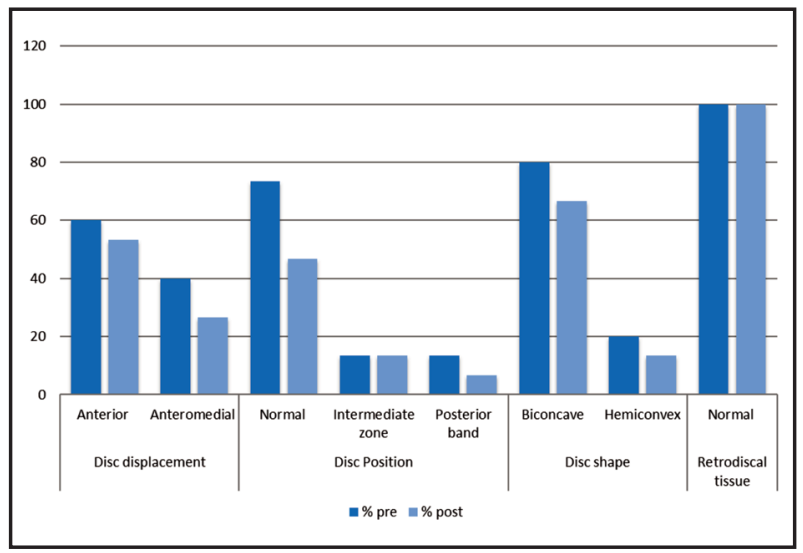

Fig. (3): Histogram showing mean values of MRI Findings

\section{DISCUSSION}

TMJ ID is one of the most common temporomandibular joint disorders. It is defined as "an abnormal positional and functional relationship between articular disc, mandibular condyle and articular surfaces of temporal bone" ${ }^{(8,9)}$

In the present study, the patients' ages ranged from 20 to 34 years, this may be explained by the fact that those patients have more responsibility in family, society, labor and bearing many life stresses. Therefore, most studies revealed this group to show higher incidence of TMJ complaints. The selected age group was in accordance with Choi et al, ${ }^{(10)}$ who found that patients between second to third decade of life had more symptoms of TMJ dysfunction, and 
Mohajerani et al, ${ }^{(11)}$ who found that the age group from 27-35 was the most common group to have TMDs signs .

In 2009, Zhang et al, ${ }^{(12)}$ had concluded that local application of simvastatin loaded on a gel vehicle of polyethylene glycol-poly lactic acid at concentration of $(5 \mathrm{mg} / \mathrm{ml})$ was found to relief pain and promote autogenous chondrogenic intervertebral disc repair and retard disc degeneration, which provides an alternative strategy for biological disc repair in a less expensive and easily applied method. From this point, simvastatin was strongly suggested to be injected intraarticulary for repair of internal derangement in humans.

Regarding the recommended dose of simvastatin injection, Than et al, ${ }^{(13)}$ in 2014 had demonstrated greater benefit of $5 \mathrm{mg} / \mathrm{ml}$ simvastatin in hydrogel than higher doses of $10 \mathrm{mg} / \mathrm{ml}$ or $15 \mathrm{mg} /$ $\mathrm{ml}$. They had claimed that higher doses were toxic to the disc secondary to altered cell membrane adipose metabolism, resulting in cell death. This was matched with injection dose in the current study where $1 \mathrm{mg} / \mathrm{ml}$ simvastatin was injected intra articulary in the superior joint space twice per month and getting gradual decrease in pain score starting from 24 hours post injection that continued up to six month.

In the present study, simvastatin injection had better comparable results regarding decrease in pain intensity. So, pain was found to be the most common clinical finding affecting patients with internal derangement. This was in accordance with Cooper and Kleinberg ${ }^{(14)}$. However, this was in contrary to Gesch ${ }^{(15)}$ who found that the most common clinical finding was deviation of the mandible followed by limitation of opening followed by pain.

Additionally, both lateral excursions and protrusive movements had shown significant improvement . This can be explained on the fact that harmony of disc condyle relationship was achieved dramatically after injection of simvastatin that denotes improvement in both lateral excursions and protrusive movements.

Regarding maximum mouth opening, the present study showed slight improvement in mouth opening after the first week from injection. These results were in accordance with studies performed by; Zhang et $a l,{ }^{(12)}$ and Then et $a l,{ }^{(13)}$ in which they proposed that simvastatin in hydrogel $5 \mathrm{mg} / \mathrm{ml}$ injection can improve the regeneration capacity of the degenerated inetrvertebral discs.

Therefore, regarding all mandibular functions, the present study results showed higher mouth opening values, lateral excursion movements and protrusive mandibular movement records in simvastatin group through different postoperative intervals. This was attributed to decrease of pain intensity after injection of simvastatin that allows harmony of articulation between the disc, condyle and articular fossa.

In the present study, MRI was used to asses: Disc displacement, Disc position, Disc shape and Retrodiscal tissue as these items had a definitive correlation in patients'improvement postoperatively. MRI findings in group I had shown a significant improvement of disc position and shape which reflects the efficacy of intraarticular simvastatin injection which was in accordance with Zhang et $a l{ }^{(12)}$ who performed intervertebral disc injection of simvastatin, and found that it retards progression of intervertebral disc degeneration induced by stab injury achieving improvement of disc position and shape

It was observed that joint sounds followed the same curve of pain intensity which means that whenever pain was remarkable joint sound was 
markedly noticed. After pain was relieved the joint sounds almost disappeared which reflects the correlation between pain and joint sounds. This was in agreement with Marklund and Wanman ${ }^{(16)}$.

Six months postoperatively MRI examination revealed that patients showed normal orientation of disc position and shape following simvastatin injection. Regarding MR imaging of patients, it was found that there was improvement in several signs of internal derangement. This was in accordance with Park et $a l,{ }^{(17)}$ who concluded similar results.

\section{CONCLUSION}

Finally, it has been concluded that simvastatin intra-articular injection proved to be able to achieve relief of pain in patients with TMJ internal derangement, allowing patients to perform their mandibular functions freely without pain.

Funding: no funding

\section{Conflicts of interest}

There are no conflicts of interest

\section{REFERENCES}

1. Shahin AA, EL Sharrawy EA, Abd El Hamid AS, Hamed TA. The Role of relaxin hormone in internal derangement of temporomandibular joint. ZUMJ. 2013;19: 317-322.

2. Manfredini D, Rancitelli D, Nardini LG. Arthrocentesis in Temporomandibular Joint Inflammatory Degenerative Disease: A randomized and controlled trial. J Cranio Func 2011;3: 41-46.

3. Vasconcelos BC, Nogueira RV, and Rocha NS. Temporomandibular Joint Arthrocententesis: Evaluation of Results and Review of the Literature. Rev Bras Otorrinolaringol; 2006; 72:634-638.

4. Draeger HT, Twining JM, Johnson CR, Kettwich SC, Kettwich LG, Bankhurst AD. A Randomized controlled trial of the reciprocating syringe in arthrocentesis. Ann Rheum Dis 2006;10:1- 4.

5. Barakat K., Ghanem AS, Elroby DH, Kasim AG. The efficacy of Simvastatin injection for treatment of perforated TMJ disc; (Experimental Study). Cairo Dental J 2016; $36: 44$.

6. Quasnichka H, Budd E, Tarlton J, Roberts S, Jackson C, Caterson B, Mobasheri A. The effect of simvastatin on novel exploratory biomarkers of cartilage degradation. Osteoarthr cartilage. 2018; 26: S19226.

7. Nitzan DW, Dolwick MF, Martinez GA. Temporomandibular Joint Arthrocentesis: A Simplified Treatment for Severe, Limited Mouth Opening. J Oral Maxillofac Surg 1991; 49:1163-1167.

8. Emshoff R, Innerhofer $\mathrm{K}$, Rudisch A, Bertram S. The Biological Concept of "Internal Derangement and Osteoarthrosis": A Diagnostic Approach in Patients With Temporomandibular Joint Pain?. Oral Surg Oral Med Oral Pathol Oral Radiol Endod 2002; 93:39-44.

9. Hayashi T, Ito J, Koyama J, Yamada K. The accuracy of sonography for evaluation of internal derangement of the temporomandibular joint in asymptomatic elementary school children: comparison with MR and CT. AJNR Am J Neuroradiol 2001; 22:728-734.

10. Choi YS, Asaumi JI, Hisatomi M, Unetsubo T, Yanagi Y, Matsuzaki H, Konouchi H, Hwang EH, and Lee SR. Analysis of magnetic resonance images of disk positions and deformities in 1,265 patients with TMD. Open Dent J 2009; 3:1-20.

11. Mohajerani S, Ghorbani Z, Gholami L, Tavakolizadeh S, and Ebrahimzadeh Z. Prevalence of TMDs among patients referred to Shaheid Beheshti dental school, Iran. Dent J Ham 2011; 21-29.

12. Zhang H, Wang L, Park JB, Park P, Yang VC, Hollister $\mathrm{SJ}$, et al . Intradiscal injection of simvastatin retards progression of intervertebral disc degeneration induced by stab injury. Arthritis Res Ther 2009; 11:R172

13. Than KD, Rahman SU, Wang L, Khan A, Kyere KA, Than TT, et al. Intradiscal injection of simvastatin results in radiologic, histologic, and genetic evidence of disc regeneration in a rat model of degenerative disc disease. Spine $\mathrm{J}$, 2014; 14:1017-1028. 
14. Cooper BC, Kleinberg I.: Examination of a large patient population for the presence of symptoms and signs of TMDs. Cranio 2007; 25114-25126.

15. Gesch D, Bernhardt O, Mack F, John U, Kocher T, Alte D. Dental occlusion and subjective TMJ symptoms in men and women. Results of the Study of Health in Pomerania . SHIP 2004;114:573-580.
16. Marklund S, Wänman A. Incidence and prevalence of TMJ pain and dysfunction. A one-year prospective study of university students. Acta Odontol. Scand 2007; 65:119-127.

17. Park JW, Song HH, Roh HS, Kim YK, Lee JY. Correlation between clinical diagnosis based on RDC/TMD and MRI findings of TMJ internal derangement. Int $\mathrm{J}$ Oral Maxillofac Surg 2021; 41:103-108. 